\title{
Nonalcoholic fatty liver disease: histopathological evaluation and interobserver agreement
}

Primeira submissão em 16/07/07 Última submissão em 23/10/07 Aceito para publicação em 26/11/07 Publicado em 20/02/08

\section{Doença hepática gordurosa não-alcoólica: avaliação histopatológica e concordância interobservador}

Cynthia Koeppel Berenstein ${ }^{1}$;Caroline Guimarães Cardoso 2 ; Nivaldo Hartung Toppa ${ }^{3}$; Virginia Hora Rios Leite ${ }^{4}$

key words
Nonalcoholic
steatohepatitis
Nonalcoholic fatty liver
disease
Steatosis
Liver

\section{abstract}

Background: Nonalcoholic fatty liver disease comprises a spectrum of lesions ranging from steatosis to cirrhosis, with nonalcoholic steatohepatitis being the progressive form of the disease. Alcohol intake, viral hepatitis and other liver diseases must be excluded. Liver biopsy is the gold standard for diagnosis of the disease and is the only method able to differentiate nonalcoholic steatohepatitis from simple steatosis, to grade inflammation and to stage fibrosis. Aims: To analyze the histopathological findings and evaluate interobserver agreement in biopsies previously diagnosed as steatosis or steatohepatitis. Methods: Seventy needle biopsies were analyzed according to Brunt et al. ${ }^{(4)}$, with modifications in the grading and staging components. Clinical data of patients were collected. Interobserver agreement was calculated based on histopathological findings. Results: Mild nonalcoholic steatohepatitis (grade 1) was the most common form. If fibrosis was detected, stage 1 was the most frequent. Interobserver agreement was very good for macrovesicular steatosis $\left(K_{w}=0,82\right)$ and good for lobular inflammation $\left(K_{w}=0,68\right)$ and fibrosis $\left(K_{w}=0,73\right)$. Conclusions: The classification of Brunt et al., with modifications, can be applied to diagnosis not only of nonalcoholic steatohepatitis but also of nonalcoholic fatty liver disease, representing a reliable method for use in the daily practice of pathologists.

\section{resumo}

Introdução: A doença hepática gordurosa não-alcoólica compreende um espectro de lesões que variam da esteatose à cirrose, sendo a esteatoepatite não-alcoólica a forma progressiva da doença. Uso de álcool, hepatites virais e outras doenças hepáticas devem ser excluídos. A biópsia hepática é o padrãoouro para o diagnóstico da doença, sendo o único método capaz de diferenciar a esteatoepatite da esteatose, graduar a inflamação e estadiar a fibrose. Objetivos: Analisar os achados histopatológicos e avaliar a concordância interobservador em biópsias previamente diagnosticadas como esteatose ou esteatoepatite. Materiais e métodos: Setenta biópsias por agulha foram analisadas segundo Brunt et al.(4), com modificações nos componentes determinantes da atividade e no estadiamento. Os informes clínicos dos pacientes foram coletados. A concordância interobservador foi calculada com base nos achados histopatológicos. Resultados: Esteatoepatite não-alcoólica discreta (grau 1) foi a forma mais comum. Se havia fibrose, o estágio 1 foi o mais freqüente. Concordância interobservador foi muito boa para esteatose macrovacuolar ( $K W=0,82)$ e boa para inflamação lobular $(K W=0,68)$ e fibrose $(K W=$ 0,73). Conclusões: A classificação de Brunt et al., com modificações, pode ser usada para o diagnóstico não somente da esteatoepatite não-alcoólica, mas também da doença hepática gordurosa não-alcoólica, representando método confiável para uso na rotina diária dos patologistas.

\section{unitermos}

Esteatoepatite não-alcoólica

Doença hepática gordurosa

não-alcoólica

Esteatose

Fígado

1. Master degree; Departamento de Anatomia Patológica e Medicina Legal, Faculdade de Medicina da Universidade Federal de Minas Cerais (UFMG).

2. Physician; UFMG.

3. Doctorate; Laboratório Analys de Anatomia Patológica.

4. Doctorate; Departamento de Anatomia Patológica e Medicina Legal, Faculdade de Medicina da UFMG.

Work conducted at the Department of Pathological Anatomy of UFMG, supported by Conselho Nacional de Desenvolvimento Cientifico e Tecnológico (CNPq), and based on the master's thesis

Doença hepática gordurosa não-alcoólica: avaliação histopatológica em biópsias por agulha e concordância interobservador, presented in 2007 to UFMG. 


\section{Introduction}

Nonalcoholic fatty liver disease (NAFLD) is considered to be the most common liver disease in the United States and has been related to insulin resistance and metabolic syndrome ${ }^{(27)}$. NAFLD comprises a spectrum of lesions ranging from steatosis, steatohepatitis and cirrhosis to hepatocellular carcinoma ${ }^{(4,6,18,33)}$. Ludwig et al. ${ }^{(23)}$ were the first to describe nonalcoholic steatohepatitis (NASH), which is currently considered to be the progressive form of NAFLD.

NAFLD is suspected when clinical examination demonstrates hepatomegaly, and/or abdominal ultrasound suggests fat accumulation in the liver, and/or mild (two to three times the reference value) and persistently elevated aminotransferase levels in individuals presenting no other cause of these alterations ${ }^{(24)}$. However, NAFLD may also occur in patients with normal aminotransferase levels ${ }^{(32)}$. Liver biopsy is considered to be the gold standard for the diagnosis of NAFLD and is the only method able to differentiate NASH from simple steatosis, to grade inflammation and to stage fibrosis ${ }^{(34)}$.

Histopathological classification systems have been proposed by Matteoni et al. ${ }^{(25)}$ for NAFLD and by Brunt et $a . .(4,6)$ for NASH. Few studies evaluating inter- and intraobserver variation of NAFLD are available. Younossi et al. ${ }^{(34)}$ used the system of Matteoni et al. ${ }^{(25)}$ and found moderate interobserver agreement for steatosis grade, location of steatosis, fibrosis stage, hepatocyte ballooning and glycogenated nuclei. Intraobserver agreement was better than interobserver agreement. Inflammation presented poor agreement between pathologists. Mendler et al.(26), proposing a scoring and grading system for NAFLD, also found that intraobserver was better than interobserver agreement. In 2005, Kleiner et al. ${ }^{(21)}$ published a report on a histological scoring system for NAFLD, which was the first and only study evaluating interobserver variation using the parameters of Brunt et al.(4). Again, inflammation showed poor interobserver agreement. It is important to remember that NAFLD-related pathologic features display considerable sample variability ${ }^{(29)}$.

Herein we analyze the histopathological findings of liver needle biopsies and determine interobserver agreement in the histological evaluation of cases with histological diagnosis of steatosis or steatohepatitis, with or without fibrosis and with no history of alcohol abuse, with emphasis on the minimal criteria for the diagnosis of NASH using the classification proposed by Brunt et al. $(4,6)$, with modifications.

\section{Materials and methods}

In a retrospective study, needle liver biopsies sent to Analys Laboratory between 1999 and 2006 with histological diagnosis of steatosis or steatohepatitis were selected. Only cases whose exam request did not report abusive alcohol use (more than $20 \mathrm{~g} /$ day) or positive serology for virus B and/or $\mathrm{C}$ were selected. Clinically, these patients presented elevated aminotransferase levels and/or alterations upon abdominal ultrasound that justified a liver biopsy. A total of 195 cases were identified.

After detailed analysis of the records, 89 cases were excluded: sample belonging to a transplanted liver $(n=10)$, heterozygous hemochromatosis $(n=5)$, alcoholism $(n=$ $35)$, presence of autoantibodies $(n=4)$, alcoholism and $C$ virus infection $(n=2)$, drug-associated hepatitis $(n=$ $1)$, no blocks available $(n=3)$, record not found $(n=7)$, and impossibility to contact the responsible physician $(n=12)$. Biopsies with fewer than five portal tracts and five centrolobular veins $(n=28)$ were excluded because they were considered to be non-representative ${ }^{(13)}$. Steatosis was a basic condition for inclusion, and cases with less than $5 \%$ of steatotic hepatocytes were defined as normal and $\operatorname{excluded}^{(5)}(n=8)$.

The remaining 70 samples were submitted to routine processing: fixation in $10 \%$ formalin, dehydration in ethanol, xylene clearing, and embedding in paraffin. The specimens were cut with a microtome and the slides were stained with hematoxylin-eosin, Masson/Gomori's trichrome, Perls' stain and picrosirius.

The slides were examined by two experienced pathologists who were unaware of the clinical/laboratory data. A specially prepared protocol was filled out based on the parameters of Brunt et al. $(4,6,7)$, with modifications. Steatosis was defined as mild (5\%-33\% of hepatocytes affected), moderate (33\%-66\%), and marked (> 66\%). Microvesicular steatosis was classified as present or absent, and its location in the acinus was recorded. Hepatocyte ballooning and glycogenated nuclei were scored as absent, occasional or frequent, and their topography was also recorded. Lobular inflammatory activity was classified as absent, mild (1-2 foci at 20x magnification), moderate (3-4 foci at 20x magnification), and marked ( $>4$ foci at 20x magnification). Portal inflammatory infiltrate was classified as absent, mild, moderate or marked, and its cellular phenotype was recorded. If no lobular activity was found, the case was classified as having only steatosis. For grading the histopathologic lesions of NASH, differing 
from Brunt ${ }^{(6)}$, the intensity of lobular inflammation was the most important feature. Ballooning and steatosis were also necessary for the diagnosis of NASH, but their intensity was not taken into account. The presence of lipogranulomas, Mallory hyalines, apoptosis and hepatic iron was recorded. If present, iron accumulation was graded. The intensity of fibrosis was divided into four categories: absent, stage 1 (fibrosis limited to perivenular area), stage 2 (perivenular fibrosis and few scattered septa), stage 3 (altered lobular architecture with septal bridging and incipient nodule formation), and stage 4 (cirrhosis). Periportal fibrosis was not considered an element in stage 2 as proposed by Brunt ${ }^{(6)}$, and scattered septa were introduced to differentiate cases with little fibrosis from cases with abundant fibrosis (which are considered stage 3).

The following data were obtained from the records: weight, height, body mass index (BMI), presence of obesity, alcohol abuse, associated diseases (arterial hypertension, diabetes mellitus and/or insulin resistance [DM/IR], and hypercholesterolemia), serum alanine aminotransferase (ALT), aspartate aminotransferase (AST) and gammaglutamyltranspeptidase (GGT), serology for $B$ and $C$ virus, presence of autoantibodies, use of hepatotoxic drugs, glycemia, total cholesterol, serum high-density lipoprotein $(H D L)$, serum low-density lipoprotein $(L D L)$, serum very low-density lipoprotein (VLDL), triglycerides, and abdominal ultrasound result.

With respect to metabolic syndrome components, patients with $\mathrm{BMI} \geq 30$ or those reported by the physician to be obese but for whom no data regarding weight and/or height were available were classified as obese. Arterial hypertension was defined as blood pressure higher than $130 \times 85 \mathrm{mmHg}$ on two or more occasions or when patients used antihypertensive drugs. IR was diagnosed when impaired fasting glucose was $\geq 110 \mathrm{mg} / \mathrm{dl}$, and type 2 diabetes mellitus (DM2) was defined as fasting glycemia $>126 \mathrm{mg} / \mathrm{dl}$. Patients using oral hypoglycemic drugs were also considered to be diabetic. Elevated cholesterol levels were defined as total cholesterol $>200 \mathrm{mg} / \mathrm{dl}$ and $\mathrm{HDL}<40 \mathrm{mg} / \mathrm{dl}$ for men and $<50 \mathrm{mg} / \mathrm{dl}$ for women. Hypertriglyceridemia was diagnosed when triglycerides levels $>150 \mathrm{mg} / \mathrm{dl}$. Patients presenting at least three of these features were classified as having metabolic syndrome ${ }^{(16)}$.

The results were submitted to descriptive analysis using the SPSS 9.0 statistical program. Interobserver agreement was evaluated using the weighted kappa test $\left(\mathrm{K}_{\mathrm{w}}\right)^{(20,30)}$ of the Stata 7.0 program. The $\mathrm{K}_{\mathrm{w}}$ coefficient was interpreted as follows: $<0.2=$ low agreement, 0.21 to $0.4=$ weak agreement, 0.41 to $0.6=$ moderate agreement, 0.61 to $0.8=$ good agreement, and $>0.8=$ very good agreement ${ }^{(30)}$.

The institution's ethics committee approved the study (ETIC 534/04).

\section{Results}

Twenty-five $(35.7 \%)$ of the 70 patients were women and $45(64,3 \%)$ were men. The mean age was 47,2 years for women and 40,4 years for men. Clinical and laboratory characteristics of the patients are shown in Table 1. Information regarding the presence of obesity was available for 47 patients. Twenty-five (53.2\%) of these patients were obese. Seventeen of the 25 obese patients presented BMI > 30 and in the remaining eight cases only the clinical record

\section{Table 1 Available clinical and laboratory findings of the 70 cases studied}

\begin{tabular}{lcccc}
\hline Clinical/laboratory finding & Number of cases & Mean & Range & Number of cases with altered values (\%) \\
Age & 70 & 42.8 & $21-73$ & - \\
BMI $\left(\mathrm{kg} / \mathrm{m}^{2}\right)$ & 36 & 29.74 & $20.2-43.2$ & $17(56.6)$ \\
Blood pressure & 64 & - & - & $19(29.7)$ \\
AST (U/l) & 63 & 48.55 & $16-198$ & $31(49.2)$ \\
ALT (U/l) & 65 & 75.92 & $10-289$ & $49(75.4)$ \\
GGT (U/l) & 59 & 117.07 & $12-574$ & $42(71.2)$ \\
Fasting glycemia (mg/dl) & 43 & 102.93 & $74-230$ & $10(23.3)$ \\
Total cholesterol (mg/dl) & 53 & 203.73 & $100-327$ & $27(51)$ \\
HDL (mg/dl) & 47 & 45.28 & $26-73.7$ & $22(46.8)$ \\
Triglycerides (mg/dl) & 44 & 189.73 & $46-697$ & $26(59.1)$ \\
\hline
\end{tabular}


of obesity was available (BMI not calculated). Nineteen of the 22 non-obese subjects had $\mathrm{BMI}<30$ and three were clinically described as non-obese.

Information regarding the glycemic profile was obtained for 45 patients. Twelve (26.6\%) subjects were classified as type 2 diabetic or resistant to insulin. Glycemia values were available for 10 of these patients and in the remaining two cases the physician informed about the presence of DM/IR. Seventeen of the 70 patients (24.3\%) presented criteria fulfilling the classification of metabolic syndrome. The AST/ALT ratio was less than one in 59 (84.2\%) cases.

Biopsies presented a mean of 10.57 portal tracts and of 8.87 centrolobular veins. These structures were not counted in two cases classified as cirrhosis.

Table 2 summarizes the histological findings and Figure shows some histopathological aspects. In 46 (65.7\%) cases,

\begin{tabular}{|c|c|c|c|}
\hline $\begin{array}{l}\text { Result } \\
\text { the } 70\end{array}$ & \multicolumn{3}{|c|}{$\begin{array}{l}\text { Results of the histological analysis of } \\
\text { the } 70 \text { liver biopsies }\end{array}$} \\
\hline & Variable & $n$ & $\%$ \\
\hline \multirow{3}{*}{$\begin{array}{l}\text { Macrovesicular } \\
\text { steatosis }\end{array}$} & Discreet & 29 & 41.4 \\
\hline & Moderate & 24 & 34.3 \\
\hline & Marked & 17 & 24.3 \\
\hline \multirow{3}{*}{$\begin{array}{l}\text { Microvesicular } \\
\text { steatosis } \\
\text { Hepatocyte } \\
\text { ballooning }\end{array}$} & Present & 42 & 60 \\
\hline & Occasional & 39 & 55.7 \\
\hline & Frequent & 31 & 44.3 \\
\hline \multirow[t]{3}{*}{ Portal inflammation } & Absent & 34 & 48.6 \\
\hline & Discreet & 31 & 44.3 \\
\hline & Moderate & 3 & 4.3 \\
\hline \multirow{3}{*}{$\begin{array}{l}\text { Lobular } \\
\text { inflammation }\end{array}$} & Discreet & 43 & 61.4 \\
\hline & Moderate & 5 & 7.1 \\
\hline & Marked & 2 & 2.9 \\
\hline Lipogranuloma & Present & 25 & 35.7 \\
\hline Mallory hyaline & Present & 10 & 14.3 \\
\hline Apoptosis & Present & 17 & 24.3 \\
\hline \multirow[t]{3}{*}{ Glycogenated nuclei } & Occasional & 18 & 25.7 \\
\hline & Frequent & 15 & 21.4 \\
\hline & Absent & 47 & 67.1 \\
\hline Hepatic iron* & Present & 22 & 33,3 \\
\hline \multirow[t]{4}{*}{ Fibrosis } & Discreet & 12 & 17.1 \\
\hline & Moderate & 7 & 10 \\
\hline & Marked & 2 & 2.9 \\
\hline & Cirrhosis & 2 & 2.9 \\
\hline
\end{tabular}

*Only 66 cases were avaiable for the study of hepatic iron.

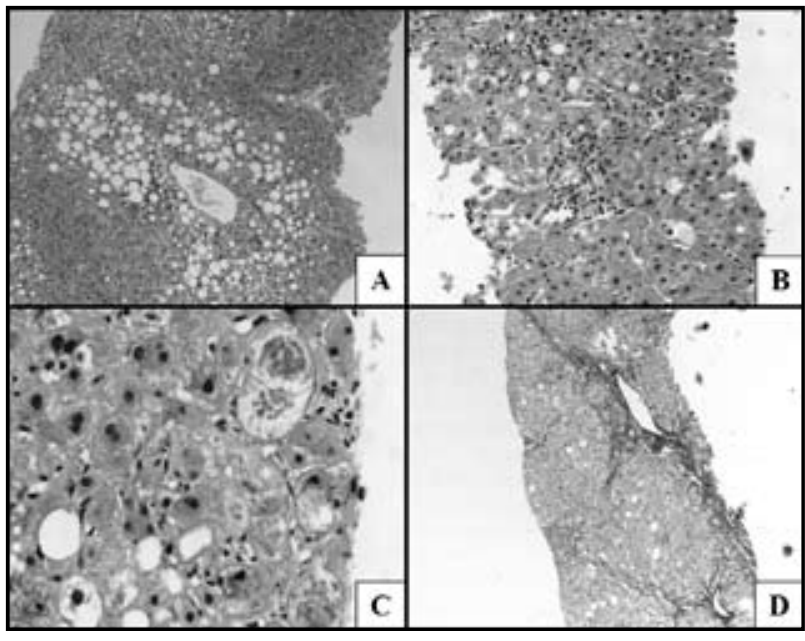

Figure - Histopathological aspects of NAFLD. A: macrovesicular steatosis around the centrolobular vein. There is a small focus of lobular activity under the vein (HE, 100x); $B$ : moderate NASH with scattered ballooned and steatotic cells (HE, 20"Ox); C: Mallory bodies in an extremely ballooned cell (HE, 400x); D: fibrosis stage 3 (Gomori's thricrome, 50x)

macrovesicular steatosis was diffusely distributed. When diffuse, moderate and marked steatosis predominated (36/46), but cases of mild steatosis (10/46) showing a diffuse distribution in the acinus were also observed. Steatosis was restricted to zones 2 and 3 in 22 (31.4\%) cases. The topography of steatosis was not determined in two (2.9\%) cases classified as cirrhosis.

Microvesicular steatosis was associated with mild steatosis in $13 / 29$ (44.8\%) cases, with moderate steatosis in $14 / 23(60.9 \%)$, and with marked steatosis in $15 / 18$ (83.3\%). In addition, microvesicular steatosis was observed in $11 / 20(55 \%)$ patients who presented no associated lobular inflammatory activity.

Hepatocyte ballooning was found in the three zones in 43 (61.4\%) cases and in zones 2 and 3 in 25 (35.7\%). The topography of ballooning was not evaluated in two cases classified as cirrhosis.

The portal inflammatory infiltrate consisted of mononuclear cells in $58.8 \%$ of biopsies and of mononuclears and neutrophils in $41.2 \%$. Lobular inflammation, defined as present when the inflammatory focus contained neutrophils, was detected in 50 cases (71.4\%). These patients were classified as having NASH. Two patients presented marked activity and corresponded to the cases of cirrhosis. No inflammatory foci were identified in 20 samples (28.6\%). Lipogranulomas were not considered as indicators of inflammatory activity.

Thirty-one (62\%) of the 50 patients classified as having NASH were males. NASH was observed in $68.9 \%(31 / 45)$ of men and $76 \%(19 / 25)$ of women. The following patients presented lobular inflammatory activity: 18 
(72\%) obese and eight (81.8\%) non-obese, 11 (57.9\%) hypertensive and 34 (75.5\%) non-hypertensive, six (50\%) DM/IR and 27 (81.8\%) non-DM/IR, 20 (74\%) with hypercholesterolemia and 17 (65.4\%) with normal total cholesterol levels, 16 (72.7\%) with low HDL levels and 17 (68\%) with HDL levels within normal limits, and 22 (84.6\%) with hypertriglyceridemia and 20 (55.5\%) with normal serum triglyceride levels. Only six (35.3\%) of the 17 patients with metabolic syndrome presented some degree of fibrosis.

Mallory hyaline was not detected in cases presenting only steatosis. In all cases they were present there was some degree of fibrosis. Mallory hyalines were frequently detected in extremely ballooning cells.

Glycogenated nuclei were located in zone 1 in 23 $(69.7 \%)$ samples and in all zones in nine (27.3\%). No topographic assessment was performed in one case (3\%) of cirrhosis. No significant association was observed between the occurrence of DM/IR and glycogenated nuclei $\left(X^{2}=\right.$ $0.89 ; p=0.34)$.

Iron accumulation determined with Perls' stain was absent in $44(62.9 \%)$ biopsies. Iron accumulation was detected in the cytoplasm of hepatocytes in four $(5.7 \%)$ cases, in Kupffer cells in six (8.6\%) and in the two cell types in $12(17.1 \%)$. In four cases the material was not sufficient for iron investigation. Hepatic siderosis was classified as grade 1 in 14 (87.5\%) biopsies and as grade 2 in two (12.5\%).

The weighted kappa test showed very good agreement for the diagnosis of macrovesicular steatosis $\left(\mathrm{K}_{\mathrm{w}}=0.82\right)$ and good agreement for the detection of lobular inflammation $\left(\mathrm{K}_{\mathrm{w}}=0.68\right)$ and fibrosis $\left(\mathrm{K}_{\mathrm{w}}=0.73\right)$.

\section{Discussion}

Predominance of NASH among women was reported up to the 1990 's. More recent reports ${ }^{(1,3)}$ have shown a similar frequency of NAFLD and NASH in both genders. Herein 45 (64.3\%) of the patients with NAFLD were men, confirming the lack of predominance among women as initially believed. The prevalence of NASH was $76 \%(19 / 25)$ among women and $68.9 \%$ (31/45) among men. Women were on average almost a decade older ( 47.2 years) than men (40.4 years) and presented a greater tendency toward inflammation, which might be explained by the lack of the protective role of hormones ${ }^{(10)}$.

The rates observed for diabetes, obesity and systemic arterial hypertension agree with literature data ${ }^{(1,3,22,23,25,28)}$.
The same was not observed for hypertriglyceridemia whose prevalence was below reported values ${ }^{(1,23)}$. Adams et al.(1) observed low serum HDL levels in 33\% (117/359) of cases, a percentage lower than that found in the present study, which was $46.8 \%$ (22/47). However, only 84 of their 435 patients were biopsied ${ }^{(1)}$, and no histological confirmation of NAFDL was therefore obtained. Regarding serum total cholesterol, Ludwig et al. ${ }^{(23)}$ observed hypercholesterolemia in $36 \%$ of patients with $\mathrm{NASH}$, in contrast to the $51 \%$ found in the present study. The metabolic syndrome component most frequently associated with NAFLD was hypertriglyceridemia, followed by obesity. Only 17 (24.3\%) of the 70 patients met criteria for the classification of metabolic syndrome. This finding shows that NAFLD should be included in the diagnostic hypothesis even in the absence of criteria for metabolic syndrome, since euglycemic and lean patients without dyslipidemias may present some form of NAFLD. Researchers have been warning since 1994(3) that the group affected by this liver disease is much larger than the group of middle-aged obese women originally described in 1989(23).

Most patients (59-84.2\%) showed an AST/ALT ratio of less than one. Three of the four cases with a ratio higher than 1.4 had at least moderate fibrosis, a finding indicating more severe disease ${ }^{(17)}$.

The classification for NASH proposed by Brunt et al. ${ }^{(4)}$ was chosen since it is the first and most widely used international classification system. The classification system described by the Cleveland group ${ }^{(25,34)}$ does not clarify whether inflammation is present in category 3 (steatosis + ballooning). In addition, different interpretations as to which categories correspond to steatohepatitis have been reported. Some authors $^{(12,17,31,35)}$ only considered categories 3 and 4 as NASH, whereas others ${ }^{(11)}$ regarded categories 2 to 4 as representative of steatohepatitis.

Mild macrovesicular steatosis was the most common alteration (41.4\%), followed by the moderate (34.3\%) and marked forms (24.3\%). In the present study, the distribution was diffuse in more than half the cases $(65.7 \%)$, with no preference for a specific zone. When diffuse, moderate and marked steatosis predominated (36/46), but a diffuse distribution in the acinus was also observed for cases exhibiting mild steatosis. Most of the 22 cases (18/22, $81.2 \%)$ in which steatosis was restricted to zones 2 and 3 presented mild steatosis. In the remaining four (18.2\%) biopsies steatosis was classified as moderate. Steatosis could not be marked since zones 2 and 3 correspond to only $66 \%$ of the acinus. The association with microvesicular steatosis 
was highly frequent, being observed in $60 \%$ of cases. In the literature, this association ranges from $34.1 \%{ }^{(19)}$ to $59 \%{ }^{(14)}$. Mendler et al. ${ }^{(26)}$ also observed macro- and microvesicular steatosis in most cases. Brunt ${ }^{(7)}$ reported that microvesicular steatosis generally occurs in more severe cases. Microvesicular steatosis was observed in cases with no lobular inflammation.

About the use of steatosis grades in the grading of NASH, we agree with Mendler et al.(26), who omitted steatosis from their score stating that it is only used to establish the diagnosis of NAFLD but is not correlated with the degree of steatohepatitis. Brunt et al. ${ }^{(4)}$ defined that in mild NASH (grade 1) steatosis might be moderate at most, and that in marked NASH (grade 3) steatosis predominantly affects more than $66 \%$ of hepatocytes. Kleiner et al. ${ }^{(21)}$ also uses the intensity of steatosis in his NAFLD Activity Score (NAS). We observed 12 cases of mild NASH (grade 1) associated with marked steatosis. In addition, one case of marked NASH (grade 3) presented mild steatosis. Thus, 13 (18.5\%) cases did not meet the classification criteria of Brunt et al.(4). Furthermore, several reports have shown that steatosis tends to decrease with the progression of the disease ${ }^{(8)}$ and might be absent in advanced cases of cirrhosis. It would thus be a contradiction to say that marked NASH can only occur with severe steatosis.

Hepatocyte ballooning was observed in $100 \%$ of the samples. However, the finding of ballooning alone does not indicate a diagnosis of NASH. This alteration is a manifestation of cell damage and occurs in response to the most variable injuries, thus being a nonspecific lesion. In the present study, ballooning was also identified in cases presenting only steatosis, a finding supporting its importance as a basic lesion of NAFLD and not only related to NASH. Ballooning was classified as occasional and frequent. Kleiner et al. ${ }^{(21)}$ divides ballooning in two categories: those with few balloon cells and those with prominent ballooning. Great difficulties in grading it were encountered during the study since this subclassification is extremely subjective. Since the minimal criteria of NASH include ballooning ${ }^{(6,7,14)}$ the determination of its presence would be sufficient.

Studies have reported prevalence of inflammation in NAFLD ranging from $25 \%{ }^{(15)}$ to $97 \%{ }^{(14)}$, with the rate of $71.4 \%(50 / 70)$ being within the reported range. Mild lobular inflammation in $61.4 \%(43 / 70)$ of the samples supports the concept that mild inflammation is present in most cases of $\mathrm{NASH}^{(7)}$. Lobular inflammation as described by Brunt et al.(4) was the only parameter used to grade
NASH, with mild inflammation corresponding to mild NASH (grade 1) and so on. Steatosis and hepatocyte ballooning are fundamental for the diagnosis of NASH, but are present at variable degrees. Thus, the presence of these two parameters is obligatory, but their quantification did not influence NASH grading.

Lipogranulomas, Mallory hyalines, apoptosis or glycogenated nuclei are not considered fundamental for the classification of NASH.

Some modifications were introduced in the classification of Brunt et al.(4) regarding the staging of fibrosis since this system includes focal and extensive alterations in the same category, with a biopsy showing focal septal fibrosis being classified as the same stage as a biopsy presenting extensive septal fibrosis. One of the characteristics of NASH is its pattern of fibrosis in zone $3^{(4,7)}$. Brunt's system ${ }^{(4)}$ classifies cases presenting focal or extensive periportal fibrosis as stage 2 , with no reference to fibrosis at zone 3 . We therefore modified her original staging and adopted the system described in the Methods section.

When present, fibrosis was mild in most cases (17.1\%). Prevalence ranging from $18 \%{ }^{(30)}$ to $38.7 \%^{(22)}$ has been reported in the literature. Cirrhosis was rare (2.9\%), with studies reporting prevalence of $0 \%{ }^{(6)}$ to $26 \%{ }^{(14)}$. Most cases were classified as stage 1 . This finding suggests that fibrosis arises as a consequence of injuries that occur in this area.

The weighted kappa test showed excellent results, with very good agreement for the diagnosis of macrovesicular steatosis $\left(\mathrm{K}_{w}=0.82\right)$ and good agreement for the diagnosis of lobular inflammation $\left(\mathrm{K}_{\mathrm{w}}=0.68\right)$ and fibrosis $\left(\mathrm{K}_{\mathrm{w}}=\right.$ $0.73)$. Similarly to the literature, inflammation was the variable that showed the largest disagreement ${ }^{(21,26,34)}$. Most of the present results were better than those reported in the literature ${ }^{(21,26,34)}$. However, one criticism might be made: if inflammation is the variable showing the lowest agreement, can it be used as the main parameter for the definition of NASH grade? We observed that well-trained pathologists obtained agreement in $68 \%$ of cases. The Gleason system, which is the most widely used for grading prostate cancer, shows a kappa index ranging from 0.47 to $0.64^{(2)}$. Nevertheless, this system is widely used. We therefore believe that, as done in the prostate, NASH can be graded with relative safety by trained pathologists.

NAFLD comprises a spectrum of lesions (steatosis, NASH, fibrosis/cirrhosis), with mild NASH (grade 1) being the most common. The determinant component for the grading of NASH was lobular inflammatory activity, characterized by a mixed inflammatory infiltrate consisting of lymphocytes and 
mainly neutrophils, which was quantified according to the classification of Brunt et al..$^{(4)}$. It is of the utmost importance that a grading system for NASH includes minimal criteria for establishment of the diagnosis, such as the presence of macrovesicular steatosis, hepatocyte ballooning and mixed lobular inflammatory foci. The classification of Brunt et al. ${ }^{(4)}$ meets these criteria. When fibrosis is present in NASH, it is generally mild and the growing deposition of collagen in zone 3 accompanied by septum formation determines its stage.
The classification of Brunt et al. ${ }^{(4)}$, initially developed for NASH and used here with modifications, can be applied to the diagnosis not only of NASH but also of NAFLD as a whole. This modified classification system can easily be applied in the daily practice of pathologists and is useful for the diagnosis of mild forms of NASH, showing very good interobserver agreement for macrovesicular steatosis and good agreement for inflammatory activity and fibrosis stage. Since the method is reliable for this diagnosis, its dissemination among pathologists is recommended.

\section{References}

1. ADAMS, L. A. et al. The natural history of nonalcoholic fatty liver disease: a population-based cohort study. Gastroenterology, v. 129, n. 1, p. 113-21, 2005.

2. ALLSBROOK, W. C. et al. Interobserver reproducibility of Gleason grading of prostatic carcinoma: urologic pathologists. Hum Pathol, v. 32, n. 1, p. 74-8, 2001.

3. BACON, B. R. et al. Nonalcoholic steatohepatitis: an expanded clinical entity. Gastroenterology, v. 107, n. 4, p. 1103-9, 1994.

4. BRUNT, E. M. et al. Nonalcoholic steatohepatitis: a proposal for grading and staging the histological lesions. Am J Gastroenterol, v. 94, n. 9, p. 2467-74, 1999.

5. BRUNT, E. M. et al. Nonalcoholic steatohepatitis: histologic features and clinical correlations with 30 blinded biopsy specimens. Hum Pathol, v. 35, n. 9, p. 107082, 2004

6. BRUNT, E. M. Nonalcoholic steatohepatitis. Semin Liver Dis, v. 24, n. 1, p. 3-20, 2004.

7. BRUNT, E. M. Nonalcoholic steatohepatitis: definition and pathology. Semin Liver Dis, v. 21, n. 1, p. 3-16, 2001.

8. BUGIANESI, E. et al. Expanding the natural history of nonalcoholic steatohepatitis: from cryptogenic cirrhosis to hepatocellular carcinoma. Gastroenterology, v. 123, n. 1, p. 134-40, 2002.

9. BURT, A. D.; MUTTON, A.; DAY, C. P. Diagnosis and interpretation of steatosis and steatohepatitis. Semin Diagn Pathol, v. 15, p. 246-58.1998

10. CLARK, J. M.; BRANCATI; F. L., DIEHL, A. M. Nonalcoholic fatty liver disease. Gastroenterology, v. 122, n. 6, p. 1649-57, 2002.

11. CONTOS, M. J.; SANYAL, A. J. The clinicopathologic spectrum and management of nonalcoholic fatty liver disease. Adv Anat Pathol, v. 9, n. 1, p. 3751, 2002.

12. COTRIM, H. P. et al. Clinical and histopathological features of NASH in workers exposed to chemicals with or without associated metabolic conditions. Liver Int, v. 24, n. 2, p. 131-5, 2004.

13. CRAWFORD, A. R.; LIN, X.; CRAWFORD, J. M. The normal adult human liver biopsy: a quantitative reference standard. Hepatology, v. 28, n. 2, p. 32331, 1998.
14. DIEHL, A. M.; GOODMAN, Z.; ISHAK, K. G. A clinical and histologic comparison with alcohol-induced liver injury. Gastroenterology, v. 95, n. 4, p. 1056-62, 1988.

15. DIXON, J. B.; BHATHAL, P. S.; O'BRIEN, P. E. Nonalcoholic fatty liver disease: predictors of nonalcoholic steatohepatitis and liver fibrosis in the severely obese. Gastroenterology, v. 121, n. 1, p. 91-100, 2001.

16. NCEP. Executive summary of the third report of the National Cholesterol Education Program expert panel on detection, evaluation, and treatment of high blood cholesterol in adults (Adult Treatment Panel III). JAMA, v. 285 , n. 19, p. 2486-97, 2001.

17. FALCK-YTTER, Y. et al. Clinical features and natural history of nonalcoholic steatosis syndromes. Semin Liver Dis, v. 21. n. 1, p.17-26, 2001.

18. FASIO, E. etal. Natural history of nonalcoholic steatohepatitis: a longitudinal study of repeat liver biopsies. Hepatology, v. 40, n. 4, p. 820-6, 2004.

19. GRAMLICH, T. et al. Pathologic features associated with fibrosis in nonalcoholic fatty liver disease. Hum Pathol, v. 35, n. 2, p. 196-9, 2004.

20. JAKOBSSON, U.; WESTERGREN, A. Statistical methods for assessing agreement for ordinal data. Scand J Caring Sci, v. 19, n. 4, p. 427-31, 2005.

21. KLEINER, D. E. et al. Design and validation of a histological scoring system for nonalcoholic fatty liver disease. Hepatology, v. 41, n. 6, p. 1313-21, 2005.

22. LEE, R. G. Nonalcoholic steatohepatitis: a study of 49 patients. Hum Pathol, v. 20, n. 6, p. 594-8, 1989.

23. LUDWIG, J. et al. Nonalcoholic steatohepatitis: Mayo Clinic experiences with a hitherto unnamed disease. Mayo Clin Proc, v. 55, n.7, p. 434-8, 1980.

24. MARCHESINI, G. et al. Nonalcoholic fatty liver disease: a feature of the metabolic syndrome. Diabetes, v. 50, n. 8, p. 1844-50, 2001.

25. MATTEONI, C. A. et al. Nonalcoholic fatty liver disease: a spectrum of clinical and pathological severity. Gastroenterology, v. 116, n. 6, p. 1413-9, 1999.

26. MENDLER, M. H.; KANEL, G.; GOVINDARAJAN, S. Proposal for a histological grading system for nonalcoholic fatty liver disease. Liver Int, v. 25, n. 2, p. 294-304, 2005. 
27. NEUSCHWANDER-TETRI, B. A.; CALDWELL, S. H. Nonalcoholic steatohepatitis: summary of an AASLD Single Topic Conference. Hepatology, v. 37, n. 5, p. 1202-19, 2003.

28. POWELL, E. E. et al. The natural history of nonalcoholic steatohepatitis: a follow-up study of 42 patients for up to 21 years. Hepatology, v. 11, n. 1, p. 74-80, 1990.

29. RATZIU, V. et al. Sampling variability of liver biopsy in nonalcoholic fatty liver disease. Gastroenterology, v. 128, n.7, p. 1898-906, 2005.

30. SIM, J.; WRIGHT, C. C. The kappa statistic in reliability studies: use, interpretation, and sample size requirements. Phys Ther, v. 85, n. 3, p. 257-68, 2005.

31. SIQUEIRA, A. C. G. et al. Non-alcoholic fatty liver disease and insulin resistance: importance of risk factors and histological spectrum. Eur J Gastroenterol Hepatol, v. 17, n. 8, p. 837-41, 2005.

32. SORRENTINO, P. et al. Silent non-alcoholic fatty liver disease - a clinical histological study. J Hepatol, v. 41, n. 5, p. 751-7, 2004.

33. YOSHIOKA, Y. et al. Nonalcoholic steatohepatitis: cirrhosis, hepatocellular carcinoma, and burnt-out NASH. Gastroenterology, v. 39, n. 12, p. 1215-8, 2004.

34. YOUNOSSI, Z. M.; DIEHL, A. M.; ONG, J. P. Nonalcoholic fatty liver disease: an agenda for clinical research. Hepatology, v. 35, n. 4, p. 746-52, 2002.

35. YOUSSEF, W. I.; McCULLOUGH, A. J. Steatohepatitis in obese individuals. Best Prac Research Clin Gastroenterol, v. 16, n. 5, p. 733-47, 2002. 